\title{
EUTOMIA
}



\section{Uma conversa com Eugenio Coseriu (1993) ${ }^{1}$}

\section{A talk with Eugenio Coseriu (1993)}

Cristina Altman' (USP)

\section{Esclarecimentos}

Conheci Eugenio Coseriu (1921-2002), como quase todos os estudantes de Letras da minha geração, pelos livros publicados em espanhol e, mais tarde, traduzidos para o Português nas décadas de 1970 e 1980 (V. COSERIU, 1979 a e b; 1980 [1968]; 1980 a e b). Eram textos indicados para os cursos introdutórios de Linguística Geral, a partir dos quais Coseriu nos era apresentado como o grande intérprete teórico do estruturalismo clássico e como o autor de conceitos que, para nós, tornavam a Linguística saussuriana operacionalizável. Do falar concreto, única realidade observável, era possível depreender nossos objetos -a norma e o sistema- por graus sucessivos de abstração. Árduos para iniciantes, os textos de Coseriu ultrapassavam em muito, como sabemos hoje, a conhecida reinterpretação do modelo langue e parole. Eram alentados estudos sobre Linguística Geral e Filologia Românica, todos devidamente contextualizados na literatura filosófica e linguística que os antecedia e acompanhados de comentários eruditos e críticos, muito além do alcance dos jovens inexperientes que éramos. Estávamos no início dos anos 1970, momento em que a

\footnotetext{
${ }^{1} O$ presente texto é uma versão escrita e resumida da Conferência intitulada Eugênio Coseriu (1921-2002) e o cenário acadêmico brasileiro dos anos 1950, proferida na Jornada de Estudo: a Linguística de Eugenio Coseriu, promovida pelo Programa de Pós-Graduação em Estudos da Linguagem, da Universidade Federal do Rio Grande do Norte, em 26 de novembro de 2021. Meus agradecimentos à calorosa acolhida da parte de todos, principalmente dos colegas organizadores Clemilton Pinheiro e Hozanete Lima.
} 
linguística brasileira mal havia se institucionalizado ${ }^{2}$ e em que a Linguística integral de Coseriu não estava ainda desenvolvida.

Quase vinte anos mais tarde, em 1993, participei pela primeira vez de uma conferência internacional da minha especialidade, Historiografia Linguística, por sugestão do meu orientador, Pierre Swiggers, para proferir uma pequena comunicação sobre minha tese de Doutorado (ALTMAN, 1993a; 1996). Tratava-se da VI International Conference on the History of the Language Sciences (VI ICHoLS), promovida pela Universidade de Georgetown, em Washington, D.C. e organizada, naquele ano, pelo professor germano-estadunidense, Kurt Jankowsky. Foi nesta ocasião que entrei em contato com vários dos scholars europeus e norte-americanos com quem vim a conviver academicamente nos anos seguintes, entre eles, Prof. Eugenio Coseriu, que me concedeu uma pequena entrevista, ou melhor, foi mais uma conversa informal que entabulamos durante um dos intervalos da Conferência.

Parte dessa conversa, gravada e confiada ao Centro de Documentação em Historiografia Linguística (CEDOCH-DL/USP) da Universidade de São Paulo, é aqui reproduzida. Nela, Coseriu menciona suas impressões sobre os profissionais brasileiros com quem manteve contato ao longo do tempo em que trabalhou em Montevideo (1951-1963); os encontros científicos de que participou; suas relações com a Biblioteca Nacional, a Academia Brasileira de Filologia e as universidades brasileiras; os cursos que ministrou na Europa como professor visitante e as conferências que proferiu no Brasil. As perguntas que formulei procuravam sobretudo sondar sua visão pessoal sobre os filólogos e linguistas brasileiros com quem conviveu ao longo da década de 1950, interessada que estava eu, naquela ocasião, em colher depoimentos 'em primeira pessoa do singular' (ALTMAN, 1995-2000) sobre a emergência de uma linguística brasileira, enquanto disciplina autônoma, institucionalizada, distinta da filologia.

Os trechos aqui reproduzidos, até então inéditos, correspondem à transcrição que realizamos na ocasião, as pesquisadoras do $\mathrm{CEDOCH}$ e eu. Salvo pequenos acréscimos, ou esclarecimentos, inseridos no texto, sempre entre chaves, ou em notas

\footnotetext{
2 A Linguística Geral, no Brasil, como disciplina distinta e autônoma em relação à Filologia, só se institucionalizou como disciplina obrigatória aos alunos de Letras em 1962.
} 
de rodapé, a conversa que tivemos (ALTMAN, 1993b) vai aqui reproduzida tal e qual, embora sem a observância das exigências técnicas das transcrições orais.

Advirta-se, ainda, ao leitor, que a reprodução que aqui se apresenta é um testemunho pessoal de Coseriu sobre um momento de transição entre duas gerações de pesquisadores brasileiros. Não deve ser entendida, pois, como uma historiografia do contexto acadêmico brasileiro da década de 1950, mas sim, como uma das fontes relevantes para essa historiografia, ${ }^{3}$ justamente porque testemunhos, em geral, vão muito além do registro de dados e fatos. Para historiógrafos e linguistas teóricos interessados no passado da sua disciplina se trata, sobretudo, de observar como os fatos selecionados por uma testemunha foram percebidos e hierarquizados. Não se pode presumir automaticamente que o que se registrou na memória daquele que dá seu depoimento corresponda à 'verdade' dos fatos. Testemunhos são inevitavelmente parciais, o que não implica que sejam necessariamente falsos. Ao contrário, as paixões de quem se dedica às atividades científicas também fazem parte da sua história (Cf. ALTMAN, 2019: Apresentação).

\section{A Conversa em 1993}

A[ltman]: Então, professor, como é que o senhor foi parar no Brasil?

C[oseriu]: Parar no Brasil?

A: Em que ano? É, porque o Sr. conhece muito bem o Brasil.

C.: Sim. Da Itália, em ano 50, eu fui ao Uruguai, como professor de Linguística Geral e, como na época ainda não havia diretor do Departamento de Linguística, [....]. Tinham fundado a Faculdade Humanidades, como chamam lá. ${ }^{4}$

A: Em Montevidéu?

C: Sim, Montevidéu. [De] lá eu tomei contato, então, com os linguistas brasileiros, também, também com os argentinos, gente que havia naquele tempo na Argentina

\footnotetext{
3 Para uma historiografia sobre o tema v., por exemplo, Altman 2021b.

${ }_{4}^{4}$ Trata-se da atual Facultad de Humanidades y Ciencias de la Educación de la Universidad de la República de Montevideo, criada em 1945.
} 
também, também no Chile, e no caso do Brasil, então, em particular com o Mattoso Câmara [1904-1970], que tinha publicado um manual muito bom...
A: Os Princípios?
C: Os Princípios, ainda na primeira edição; depois, aumentou muito, né?5

A: umhum....

C: Eu utilizava também nas aulas, na [...], e também muito [contato] com o Serafim da Silva Neto [1917-1960]. Então, muito mais tarde, já tínhamos correspondência com [inaudível...], eles mandavam separatas, eu mandava também, então, não me lembro exatamente quando foi, mas acho que foi no 56 , sim, então eu fui, por minha iniciativa, ao Brasil para me encontrar com a gente, em particular com Silva Neto, mas então tomei contato com os outros, com todos, não. Então estava o Diretor da Biblioteca Nacional...[... $]^{6}$
A: Nascentes?
C: Não, não, estava aquele que morreu, há pouco...

A: Celso Cunha?

C: Celso Cunha [1917-1989], Celso Cunha, então conheci o Mattoso, os outros, o Sílvio Elia [1913-1998], o Ernesto Faria [1906-1962], o Antenor Nascentes [1886-1972]...
A: Todos filólogos, ou essa questão não se colocava na época?
C: Como?

A: Eles eram filólogos, o Sr. se considerava filólogo também ou não?

C: Sim, sim, sim, filólogos e linguistas também porque aí não, ainda [não] faziam a diferença entre filólogos e linguistas, quer dizer, mas eu [os] conhecia pelas publicações do Antenor Nascentes, e também, e, lá então estabeleci este contato, muito mais, quer dizer, intenso, e ao mesmo tempo permanente, já com os brasileiros, né, mais com os brasileiros do Rio, em particular. E também conheci os outros, o [Gladston] Chaves de Mello [1917-2001], naquela época, ainda, acho que ainda vivia o [Álvaro Ferdinando] Sousa da Silveira $[1883-1967] \ldots$

\footnotetext{
${ }_{5}^{5}$ Mattoso Câmara Jr., Joaquim. Princípios de Linguística Geral como fundamento para os estudos superiores da língua portuguesa. $1^{\mathrm{a}}$ ed. Rio de Janeiro: Briguiet. [Reimpr., 1942; $2^{\mathrm{a}}$. ed. rev. e ampl. Rio de Janeiro: Acadêmica, 1954; $3^{\mathrm{a}}$ ed. rev. e ampl.,1959; $4^{\mathrm{a}}$ ed. rev. e ampl,1967. As demais edições seguem a $4^{\mathrm{a}}$ ] ${ }^{6}$ Fundação da Biblioteca Nacional, Rio de Janeiro, desde 1808.
} 
A: Ainda, em $56 \ldots$

C: Sim, sim, e os outros, lá de, como é que chama ele? Olmar Guterres [da Silveira] (?-

?) que publicou uma edição da gramática do Fernão de Oliveira [O.P. 1507-post 1581], ${ }^{7}$

e muita gente mais. O Adriano da Gama Kury (1924-2012), os jovens...

A: O Sr. lembra de todos, né?

C: Sim. Então, eu acho que foi já o ano seguinte, ou mais tarde, talvez já 58.

A: Em 58 o Mattoso conseguiu [formar] um centro de Linguística, no Museu Nacional. ${ }^{8}$

C: Sim, em 58 houve um grande congresso de ... eu acho que foi em 58 , Dialetologia...

A: e Etnografia...

C: E Etnografia, em Porto Alegre. ${ }^{9}$

A: Muito bem, 58, que memória!

C: Então, eu já fui convidado, então também, com uma palestra, também, então, nessa época, em 56, série de palestras, na Biblioteca Nacional e na Universidade do Celso Cunha. ${ }^{10} \mathrm{E}$ também, como chama, a Petrópolis, lá também, havia um centro... ${ }^{11}$

A: Desculpa, professor, em 56, o grande nome no Brasil quem era? Silva Neto ou Mattoso Câmara?

C: O grande nome...

A: A grande referência.

\footnotetext{
${ }^{7}$ A "Grammatica" de Fernão d'Oliveyra. Texto reproduzido do da $1^{\text {a }}$ ed. e apreciação de Olmar Guterres da Silveira. Rio de Janeiro: Jornal do Commercio - Rodrigues \& C. a , 1954. Agradeço a referência completa ao colega de Vila Real, Carlos Assunção.

${ }^{8}$ Museu Nacional, Setor Linguístico, 1958, dedicado principalmente ao estudo das línguas indígenas brasileiras (cf. ALTMAN, 2004 [1998]: 107).

9 / Congresso de Dialetologia e Etnografia, de 1958, em Porto Alegre. Neste momento, a dialetologia se consagrava no Brasil como linha preferencial de pesquisa. No encontro, Coseriu proferiu a comunicação sobre "Los conceptos de dialecto, nivel y estilo de lengua y el sentido propio de Dialectología". Estão aí as conhecidas distinções entre variedades espaciais (diatópicas), variedades socioculturais (diastrásticas) e variedades expressivas (diafáticas/ diafásicas). Na sua proposição, a dialetologia é o estudo dos dialetos enquanto variedades diatópicas, distinta da gramática estrutural que deve descrever o que há de homogêneo na língua histórica. Publicado mais tarde, com revisões, em Linguística Española Actual 3.1: 1-32, 1981 e, ainda, sob o título "Sentido y Tareas de la Dialectología", México, Instituto de Investigaciones Filológicas, Centro de Lingüística Hispánica, Cadernos de Lingüística de la ALFAL no. 8, 1982 (V. ALTMAN, 2017).

${ }^{10}$ Universidade Federal do Rio de Janeiro (UFRJ), a partir de 1965. No período a que Coseriu se refere, tratava-se da Faculdade Nacional de Filosofia da Universidade do Brasil (c.1939-1965).

${ }^{11}$ Com certeza Coseriu se referia à Pontifícia Universidade Católica de Petrópolis, onde Mattoso foi professor até sua morte, em 1970.
} 
C: O grande nome era o Silva Neto ${ }^{12} \ldots$

A: O Silva Neto.

C: Sim, o Silva Neto, porque o Mattoso Câmara, também no sentido que falam agora, da instituição, ele ainda não, a sua linguística não estava institucionalizada, e ele ficava não? um pouco fora do grupo; não, também não tinha uma cadeira na Universidade, ele tinha uns cursos assim, ele se tinha apresentado, mas tinha ganhado o Celso Cunha. ${ }^{13}$
A: Não diga?
C: Sim, sim, mas que não era de Linguística Geral, era de Língua Portuguesa, alguma coisa assim...

A: Filologia Portuguesa, talvez...

C: Filologia Portuguesa, alguma coisa assim, não? Linguística Geral não havia, na realidade havia assim, um curso, não havia uma cadeira. Aliás, o outro, o Serafim da Silva Neto, sim, ele tinha se formado sozinho, era também, pela família, homem de muito dinheiro, ele também não precisava muito isso, mas também não tinha ganhado na primeira vez, a cadeira que era então de Filologia Românica ou de Línguas Românicas, porque a tinham dado ao Padre Augusto Magne [1887-1966]...
A: Augusto Magne...
C: Porque, [Magne era um] homem muito mais velho, e considerado mestre da Filologia por eles...

A: E o Silva Neto era muito moço, então, né?
C: Sim, o Silva Neto, ele morreu ainda muito jovem...
A: Quarenta e poucos, né?
C: Sim, eu acho que quarenta e dois, alguma coisa $\operatorname{assim}^{14} \ldots$

\footnotetext{
${ }^{12}$ Quase todos os scholars mencionados por Coseriu trabalhavam no Rio de Janeiro, ou em Filologia Românica, ou em Filologia Portuguesa, e, caso não trabalhassem no Rio, frequentavam suas instituições, como o Centro de Pesquisas Filológicas da Casa de Rui Barbosa, por exemplo (cf. Rossi 1965: 13). O centro principal de irradiação das ideias linguísticas nos anos 50 era, de fato, o Rio de Janeiro, e seu líder intelectual e organizacional (nos termos de Murray 1994) era, como reconheceu o próprio Coseriu, Silva Neto (v. também COELHO, 1998; e ALTMAN, 2021).

${ }^{13}$ Mattoso teria se apresentado como candidato à Cadeira de Língua Portuguesa da Faculdade Nacional de Filosofia da Univ. do Brasil, em 1956, mas Celso Cunha ficou com a vaga. Ao que consta, Mattoso acabou por retirar sua candidatura antes do concurso, sem mágoas.

${ }^{14}$ Silva Neto morreu em 1960, aos 43 anos.
} 
A: É, muito jovem...

C: Mas ele tinha começado muito, muito jovem, ele tinha começado com 17 anos, já tinha publicado as Fontes do Latim Vulgar, não, [risadas], ${ }^{15}$ e então ele [...], em 57, ele já era a figura dominante, ele tinha começado a publicar História da Língua Portuguesa, ${ }^{16}$ ele já tinha publicado muitas coisas, e era também o homem que tinha a maior biblioteca de Linguística, tinha uma coisa enorme, biblioteca...

A: O Sr. chegou a conhecer essa biblioteca, famosa biblioteca?

C: Sim, sim, depois, infelizmente, quase desapareceu, a biblioteca; já sabe, né, o que aconteceu, ficou lá na chuva, fora da Faculdade...

A: Não, eu não sabia...

C: Sim, sim, ele morreu, e eu acho que a viúva ou a família, porque, tinha perdido também o filho, então vendeu a, quer dizer, a Faculdade comprou a biblioteca, que era a biblioteca melhor de linguística de toda a América Latina, era uma coisa incrível que ele tinha...

A: É verdade. O Sr. comenta isso no artigo. ${ }^{17}$

C: Sim, ele tinha. Então, e não só de Linguística Românica ou de Linguística Portuguesa, ele tinha também muitíssimo, muitíssimo de Linguística Geral, e coisas que ninguém tinha, ele tinha pessoalmente e comprava na Europa, nas viagens, tinha manuscritos também, tinha uma coisa incrivel. Mas, então, esta biblioteca eu acho que, o que me disseram é que foi comprada, e então levaram-na em caminhões, lá na Universidade, nesta ilha onde é que fica a Universidade...

A: Fundão, na Federal [UFRJ] ...

C: Sim, sim e ficou fora em caixas e houve greve por muitíssimo tempo. Muitíssimo tempo. E parece, então, que choveu, isso e...

A: E deixaram lá...

C: E que estragou-se. Estragaram-se muitíssimos livros, e, é o que me disseram...

\footnotetext{
${ }^{15}$ Fontes do Latim Vulgar. O Appendix Probi. Rio de Janeiro, 1938; $3^{\mathrm{a}}$ ed., 1956. Até onde pude verificar, Serafim da Silva Neto teria começado a escrever as Fontes, de fato, aos 17 anos.

${ }^{16}$ História da Língua Portuguesa. Rio de Janeiro: Livros de Portugal. Publicada em fascículos, de $1952\left(1^{\text {a }}\right.$ ed.) a 1957.

${ }^{17}$ V. Coseriu (1976[1968]).
} 
$A:[\ldots]$

C: Sim, sim, isso, não sei, verifique, não sei, não sei se...

A: Essas estórias se apagam, mas é bom a gente saber, e denunciar um pouco isso... ${ }^{18}$

C: Então, sim, porque ele tinha levado essa biblioteca lá, já para a colocar e depois começou com isso, já greve e isso, e ficou fechada a Universidade acho que muitíssimo tempo...

A: O Sr. lembra o ano mais ou menos?

C: Não, não. Isso foi depois, já depois da morte do Serafim Silva Neto ...

A: Grande greve... Na 'revolução', Talvez...

C: Talvez...

A: $63,64 \ldots$

C: Disseram que o Silva Neto, [que] ele tinha ido a Portugal, também como professor visitante da Universidade de Lisboa. ${ }^{19}$ Porque os portugueses não tinham, na realidade, já professores, muito poucos, de gramática histórica, história da língua. Então, isso faziam os brasileiros em Portugal, que foi o [que] Serafim [fez], um ano, dois anos depois, foi, também foi o Mattoso ${ }^{20}$, também, lá. Talvez depois foi o Sílvio Elia, ${ }^{21}$ depois também o Evanildo Bechara. ${ }^{22}$ Eles sempre convidam algum brasileiro para esta cadeira de Linguística, não sei se é em Lisboa, ou em Coimbra. Então, quer dizer, porque não tem número suficiente de professores, porque, na realidade, os dois são, agora morreu também um deles, o [Luís Filipe] Lindley Cintra (1925-1991) e o outro, o [José Gonçalo] Herculano de Carvalho (1924-2001), não..., estava em Coimbra, mas não, estava muito doente e... Mas isso já antes, já naquela época parece ... Então, com este congresso ficaram já estabelecidas as relações, muito bem, isso com toda a gente, também de Porto Alegre, também então, também de Curitiba, que era o, eu acho que lá era o [Rosário Farani] Mansur Guérios (1907-1987), era professor lá em Curitiba, com outra gente também, alguma gente de São Paulo, com...

\footnotetext{
${ }^{18}$ Até o momento não consegui triangular fontes independentes sobre o presumido fato. Recomendo cautela, portanto, ao leitor, antes de assumir o relato de Coseriu.

19 Provavelmente entre 1958 e 1960.

${ }^{20} \mathrm{Na}$ Universidade de Lisboa, entre 1962 e 1964.

${ }^{21} \mathrm{Na}$ Universidade de Lisboa, entre 1964 e 1966; e em Coimbra, 1969.

${ }^{22}$ Em Coimbra, entre 1987 e 1989.
} 
A: Com certeza o Heinrich Bunse, do Rio Grande do Sul...

C: De Belo Horizonte [...], lá no Rio Grande do Sul estava o, para a Filologia, o Albino de Bem Veiga (?-?), o.... não sei se estava lá ou estava em Florianópolis, um alemão, o Bunse. ${ }^{23}$ E depois, alguma gente de lá, mais tarde, de Belo Horizonte, com a Sra. [Angela] Vaz Leão (n. 1922).

A: Ela [Angela V. Leão] ainda está lá...

C: Sim, e de São Paulo, estava o Theodoro Henrique Maurer Júnior (1906-1979), ${ }^{24}$ estava a Madre Olívia (?-1994) $)^{25} \ldots$

A: Só em 58, a Madre Olívia?

C: Sim, eu acho que sim, ou senão mais tarde, mas acho que deve ser naquela época, porque, depois, uns poucos anos depois eu vim para a Europa, então já não [...]. Então, depois ainda, a última coisa no Brasil foi um grande congresso luso-brasileiro na Bahia. ${ }^{26}$ Então, em Salvador, então, e lá, sim, estava também gente de Salvador, o Nelson Rossi (1927-2014); lá, também participei, neste congresso, e antes, então e foi uma coisa que durou muito e organizada também, em parte pelo Celso Cunha e pela Academia Brasileira de Filologia então, a volta, então, ficamos ainda no Rio, uma semana, ou duas semanas. Mas eu, entre o Congresso da Bahia e do Rio, então, fui convidado ainda para dar palestras lá no Norte, e tinha de ir à Fortaleza, Belém, mas só fui à Fortaleza, lá estava um homem: Florival Seraine (1910-1999).

A: Ah, é isso mesmo! Médico, mas dialetólogo...

C: $\operatorname{Sim}, \operatorname{sim}$.

A: Que memória! Ele mesmo. O Florival Seraine ...

\footnotetext{
${ }^{23}$ Heinrich Adam Wilhelm Bunse (1911-1990) foi professor e catedrático de Filologia Românica na Faculdade de Filosofia, Ciências e Letras da Universidade do Rio Grande do Sul, de 1947 até 1966.

${ }^{24}$ Maurer assumira a Cadeira de Filologia Românica, na Universidade de São Pulo, em 1947.

${ }_{25}$ Cília Coelho Pereira Leite, conhecida como Madre Olívia, foi docente e pesquisadora na Faculdade de Filosofia Ciências e Letras Sedes Sapientiae, da Pontifícia Universidade Católica de São Paulo, de 1957 até sua morte, em 1994.

${ }^{26}$ IV Colóquio Internacional de Estudos Luso-Brasileiros, realizado em Salvador, em 1959. Na ocasião, Coseriu teria proferido comunicação Sobre las llamadas construcciones con verbos de movimento: un problema hispânico. Em http://www.romling.unituebingen.de/coseriu/publi/coseriu25.pdf. Os Anais do IV Colóquio a que tive acesso, mencionam, entretanto, na Seção II, dedicada à Língua, outro título para a comunicação de Coseriu, mais afeito, aliás, ao tema do colóquio: Caracteres fundamentales del léxico português.
} 
C: Sim. E também havia um de Linguística Aplicada, que havia publicado um livro, bonzinho, o Valnir Chagas (1921-2006), não sei se conhece...

A: umhum ... Valnir Chagas, já ouvi falar, só não conheço nada dele...

C: Então, depois a volta então, novamente no Rio, então, lá me fizeram já sócio da Academia Brasileira de Filologia. E com isso já acabou-se esta época. Não sei se depois ainda...Sim, depois ainda me convidaram ainda para Porto Alegre também assim, também para um ciclo de palestras e depois, em 61, eu voltei à Europa, como professor visitante da Universidade de Bonn, e o ano seguinte também, e também em... Em 61, primeiro... Ou 6o já? Eu fui à Universidade de Coimbra, dois meses ou três meses. Foi então, por intermédio do Herculano de Carvalho, tínhamos nos conhecido neste, já no primeiro, primeiro Congresso de Porto Alegre, ${ }^{27}$ eu fui seu relator lá, e ele foi relator meu no outro Congresso, Congresso da Bahia, ${ }^{28}$ então ele falou lá nesta sociedade que eles têm, nesta fundação, a [inaudível] ${ }^{29}$..., então convidou-me como professor visitante à Coimbra. Eu acho que isso foi anos 60 e começo de 70.

A: Então, o Sr. ficou digamos na América do Sul durante cinco anos?

C: Não, na América do Sul até 63, porque eu fui a Portugal, depois voltei novamente, depois a Bonn, voltei novamente, depois...

A: Ah, o Sr. voltou...

C: Quer dizer, definitivamente eu fiquei 12 anos na América do Sul.

A: 12 anos na América do Sul!

C: 12 anos. Então, o último foi 6o, quer dizer... Eu cheguei em 51... Sim, 51, então comecei lá. E deixei o Uruguai em abril do 63, então, cheguei...

A: Doze anos, doze anos...

C: Sim, exatamente doze anos. Mas com essas interrupções, porque tinha estado na...

A: Sim, participações, idas e vindas.

\footnotetext{
27 Trata-se do já mencionado I Congresso Brasileiro de Dialetologia e Etnografia, realizado em Porto Alegre, em 1958.

${ }^{28}$ Trata-se do também já mencionado IV Colóquio Internacional de Estudos Luso-Brasileiros, realizado em Salvador, em 1959.

${ }^{29}$ É possível que ele tenha se referido à Fundação Calouste Gulbekian.
} 
C: Sim, também tinha ido para esse curso de verão no Chile, duas vezes, do Uruguai mesmo, muitas vezes à Argentina, para, também, porque estavam os júris que tinham deles para ocupar as cadeiras, né, depois da primeira ou segunda revolução, porque eles tiveram muitas.

A: É verdade, é verdade, eles também tiveram...

C: É. Mas assim, foi a relação com o Brasil. Mas depois, quando eu já estava na Alemanha, em 63, já em Tübingen, escreveu-me alguém, não sei quem, da... Talvez tenha sido este mesmo, o [Thomas] Sebeok (1920-2001)... Para eu participar na... Um panorama da Linguística na América Latina, neste volume do Current Trends...

A: Ah, sei, acho que é o volume 13, sobre...

C: Não, não, muito antes, acho que é $4 \cdots .^{30}$

\section{Observações Finais}

À guisa de conclusão, retomo nesta crônica parte das conclusões de trabalhos anteriores (v. principalmente Altman 2021b). No início da década de 1960, como se sabe, Coseriu passou um período como professor visitante na Universidade de Coimbra (1960) e nas Universidades de Bonn e Frankfurt (1961, 1962), pouco antes de deixar definitivamente a América do Sul, em 1963, para se radicar definitivamente em Tübingen, época em que a rede brasileira por onde circulava Coseriu aqui se dispersou. Dispersaram-se também as tarefas a que esta geração havia se proposto: o estudo histórico do português, a descrição do falar brasileiro e a elaboração de atlas regionais. A ruptura que ocorreu no Brasil entre a disciplina Filologia e a disciplina Linguística, que reivindicou a partir dos anos 1960 autonomia institucional, teórica e metodológica, acabaria por circunscrever Coseriu na órbita dos filólogos brasileiros e dos primeiros estruturalistas europeus que era mister ultrapassar. Em outras palavras, Coseriu seria percebido nos anos subsequentes à sua ida definitiva para a Alemanha como um dos scholars que estavam a meio caminho das orientações tradicionais em matéria de pesquisa linguística e das propostas mais 'modernas', que mal tinham adentrado no

\footnotetext{
${ }^{30}$ Coseriu tinha razão, era o volume 4. V. Coseriu (1976 [1968]).
} 
país. Coseriu encontraria espaço junto às novas gerações, principalmente, como um crítico do estruturalismo clássico, e não como o autor de modelos teóricos a serem apreciados no âmbito de uma nova Linguística que então apenas apontava no horizonte. Seriam necessárias mais algumas décadas para ver sua Linguística Geral ressurgir entre os pesquisadores contemporâneos como quadro de trabalho pósestruturalista, a ser revisitado nas análises linguísticas do presente (cf., por exemplo, a Revista de la Academia Nacional de Letras 10:13, 2017, Montevideo; e a presente Jornada de Estudo: a Linguística de Eugenio Coseriu, Universidade Federal do Rio Grande do Norte, 2021).

\section{Referências}

ALTMAN, Cristina. Unificação e Diversificação da Linguística: pesquisa documental de produção linguística brasileira contemporânea (1968-1988). Universidade Católica de Louvain, Bélgica e Universidade de São Paulo, Faculdade de Filosofia, Letras e Ciências Humanas, 1993 a.

ALTMAN, Cristina. Entrevista concedida a Cristina Altman. VI International Conference on the History of the Language Sciences (VI ICHoLS), promovida pela Universidade de Georgetown, em Washington, D.C. MS inédito, 1993b.

ALTMAN, Cristina (coord.) 1995-2000. A linguística no Brasil: estórias e histórias em primeira pessoa do singular. Projeto de mapeamento das primeiras gerações de linguistas que atuaram no cenário acadêmico brasileiro nas décadas de 1960 e 1970. Universidade de São Paulo: CEDOCH DL-USP. [Retomado em 2020 com o nome de Em Primeira Pessoa do Singular e outras crônicas. Projeto de mapeamento das primeiras gerações de mulheres linguistas que atuaram no cenário acadêmico brasileiro nas décadas de 1960 e 1970.]

ALTMAN, Cristina. Linguistic research in Brazil (1968-88). In: Jakowsky, K. (ed.) Multiple perspectives on the historical dimensions of languages. Münster: Nodus Publikationen, 1996, p. 163-170.

ALTMAN, Cristina. A pesquisa linguística no Brasil. $2^{\text {a }}$ ed. São Paulo: Humanitas, 2004 [1998].

ALTMAN, Cristina. Eugenio Coseriu entre a Filologia e a Linguística Brasileira (19501963). Revista de la Academia Nacional de Letras, 13, 2017, p. 97-117. 
ALTMAN, Cristina. Apresentação. In: Oliveira, Miguel (Org.). 50 Anos de Abralin. Memórias e perspectivas. Campinas: Pontes, 2019, p. 5-12

ALTMAN, Cristina. A guerra fria estruturalista. Estudos em Historiografia Linguística brasileira. São Paulo: Parábola, $2021 a$.

ALTMAN, Cristina. Eugenio Coseriu: entre a Filologia e a Linguística brasileiras (19501963). In: ALTMAN, Cristina. A guerra fria estruturalista. Estudos em Historiografia Linguística brasileira. São Paulo: Parábola, 2021b, p. 177-188.

COELHO, Olga. Serafim da Silva Neto (1917-1960) e a Filologia Brasileira: Um ensaio historiográfico sobre o papel da liderança na articulação de um paradigma em ciência da linguagem. Dissertação de Mestrado. Universidade de São Paulo: Faculdade de Filosofia, Letras e Ciências Humanas, 1998.

COSERIU, Eugenio. Perspectivas gerais. Tendências atuais da linguística e da filologia no Brasil, org. por Anthony J. Naro. Rio de Janeiro, Francisco Alves, pp. 11-44. (Trad. de Maria Cândida D. Bordenave do orig. inglês: Brazilian Linguistics. Current trends in the language science ed. por Thomas Sebeok, 1968. Ibero-American and Caribbean Linguistics vol. 4. Haia, Mouton.), 1976 [1968].

COSERIU, Eugenio. Sincronia, diacronia e história. O problema da mudança linguística (Trad. de Carlos Alberto da Fonseca e Mário Ferreira). Rio de Janeiro/São Paulo: Presença/ EDUSP, 1979a.

COSERIU, Eugenio. Teoria da linguagem e linguística geral: cinco estudos (Trad. de A. Dias Carneiro e rev. de Carlos Alberto da Fonseca e Mário Ferreira). Rio de Janeiro/São Paulo: Presença/ EDUSP, 1979b.

COSERIU, Eugenio. Lições de linguística geral (Trad. de Evanildo Bechara, rev. e corrig. pelo autor). Rio de Janeiro: Ao Livro Técnico, 1980a [1968].

COSERIU, Eugenio. Panorama da linguística ibero-americana (1940-1965). In: COSERIU, Eugenio. Lições de linguística geral (Trad. de Evanildo Bechara, rev. e corrig. pelo autor). Rio de Janeiro: Ao Livro Técnico, 198ob [1968], p. 277-368.

COSERIU, Eugenio. Tradição e novidade na ciência da linguagem: estudos de história da linguístic, (Trad. de Carlos Alberto da Fonseca e Mário Ferreira), Rio de Janeiro/São Paulo, Presença/ EDUSP, 1980c.

MURRAY, Stephen O. Theory groups and the study of Language in North America. A social history. Amsterdam: John Benjamins, 1994. 
ROSSI, Nelson. Atlas prévio dos falares baianos. [Introdução, questionário comentado, elenco das respostas transcritas.] Instituto Nacional do Livro: Ministério da Educação e Cultura, 1965.

\footnotetext{
${ }^{i}$ Doutora em Linguística pelas Universidades Católica de Louvain (Bélgica) e de São Paulo. Realizou estágios pós-doutorais na Universidade de Harvard e no M.I.T.; na Universidade de Amsterdam; no Instituto Iberoamericano de Berlin, em duas ocasiões, e na Universidade de Tokyo. É Professora Titular do Departamento de Linguística da Universidade de São Paulo.
}

ORCID: http://orcid.org/0000-0002-5121-4282.

E-mail: altman@usp.br.

Recebido em 09/12/21

Aprovado em 04/01/22

Todo conteúdo da Revista Eutomia está sob a Licença Creative Commons Atribuição 4.0 Internacional. 